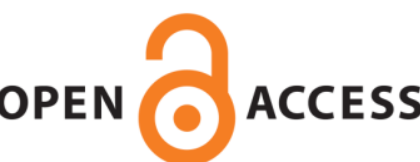

UWS Academic Portal

\title{
Exploring a taboo of cultural reproduction
}

Holligan, Christopher

Published in:

British Journal of Sociology of Education

DOI:

$10.1080 / 01425692.2017 .1367270$

E-pub ahead of print: 24/08/2017

Document Version

Peer reviewed version

Link to publication on the UWS Academic Portal

Citation for published version (APA):

Holligan, C. (2017). Exploring a taboo of cultural reproduction. British Journal of Sociology of Education, 39(4), 535-550. https://doi.org/10.1080/01425692.2017.1367270

\section{General rights}

Copyright and moral rights for the publications made accessible in the UWS Academic Portal are retained by the authors and/or other copyright owners and it is a condition of accessing publications that users recognise and abide by the legal requirements associated with these rights.

\section{Take down policy}

If you believe that this document breaches copyright please contact pure@uws.ac.uk providing details, and we will remove access to the work immediately and investigate your claim. 


\title{
EXPLORING A TABOO OF CULTURAL REPRODUCTION
}

\begin{abstract}
Cultural reproduction is rarely, if ever, theorised through clandestine practices of sexual offending by teachers in the gendered hierarchies of state schools. Drawing upon Freedom of Information requests and other official qualitative data provided by a UK teaching council this paper endeavours to explain the form of a gendered cultural reproduction by reference to the diversity of ways in which identities are constructed and 'contracted' for female student victims. The paper begins by looking at this taboo subject matter in the context of a historical patriarchal order and cultures of heterosexuality in schools, followed by a feminist perspective through which empirical theorization is documented. Michel Foucault's work on the micro-physics of power and normativity informs the emphasis of the contemporary feminist prism. It is argued that that offending occurs under the auspices of the professional teacher-student hierarchy and produces distinctive and damaging power effects.
\end{abstract}

Keywords: abuse; feminist; gender; heterosexual; identity; schools; sexual.

\section{HETEROSEXUAL DOMINATION}

"Gender norms operate through constant internal enforcement in each of us as we daily prepare our appearances, modulate our voices and gaits and feel shame about our bodies as we move through all the institutions of social control and deviance 
management that are authorised to intervene directly on the bodies of those categorised as violating these norms" (Spade and Willse 2015).

An illicit and unprofessional 'gaze' at women in general is symbolic of processes of gender domination by men designed to encourage passivity in women, rendering a submissive subjectivity where they create themselves as sensual ornaments (de Beauvoir $\{1949\} 1989$; Low 2006: 127). Cultural reproduction of the gender order also occurs secretly within the ambit of an institution of social control, as this paper explores, where a code of taboo arguably intensifies the depth of an objectification of woman as sexual objects, rendering them as docile bodies. The romance myth's normativity may underlie the symbolic violence of this political entrapment of a feminine embodiment. Feminism aims to expose and understand power relations between men and women (Dillabough 2003; Oksala 2015). The word 'taboo' was introduced into European languages by Captain Cook who had observed avoidance customs in his third voyage when he visited Polynesia (Milner 2012). It is now a descriptive category of ethnography employed typically to designate the prohibited and forbidden (Douglas 1966; Freud 1950; Steiner 1967). It is an orthodoxy on research about misbehaviour in schools that it looks 'downwards' at pupils; by looking 'upwards' at teachers this paper engages with displays of hierarchical power. Foucault's recommendation is that power relations need to be analysed primarily at the grass roots (Foucault 1978, 1982).

As recently as 1975 a renowned Scottish academic historian remarked "It is sad ...that research into sexual history should generally appear to be either prurient or trivial: if social history aims to reflect what is important in people's lives, sexual history deserves much more serious and central attention" (Smout 1975: 55). Scholarly knowledge of this understandably sensitive field is severely limited; conceptualised as a societal taboo deemed to pollute, it is avoided (Douglas 1966; Sikes and Piper 2010). Using official statistics and narrative data this paper offers a sober sociological treatment of sexual offending in secondary school state 
education. The General Teaching Council for Scotland (GTCS) and its equivalent body in England, the GTC aim to regulate legitimate behaviour and prescribe boundaries of professional standards. These are extensive in their societal scope as a teacher's behaviour both inside and outside school is encompassed.

The organisation of the paper for reporting this empirical study is as follows: firstly, studies of sexuality and gender are explored, taking account of education, emphasizing the variable of gender and acknowledging class dimension. Following this section feminist reproduction theory is reviewed and Foucault's perspective on power appropriated (Threadcraft 2015; Oksala 2015; Spade and Willse 2015). To analyse social phenomena feminist theory looks at identities, practices and domination and subordination (Disch and Hawkesworth 2015). Thirdly, it is against this background of very recent feminist reproduction theory and substantive knowledge that the empirical study is contextualised (Disch and Hawkesworth 2015). The conceptual framework developed for the data analysis is respectful of the paper's contemporary feminist theorising. Research questions posed are: how do practices of heterosexual sexual offending produce heterosexual identities in girls? And, relatedly how do the involved relations of power involved operate?

Teachers who work as porn actors whilst also employed as teachers are deemed in breach of professional standards. Adopting exaggerated sexual identities in public is a professional taboo. BBC News (1.9.2011) reported the moonlighting as a male stripper of a male secondary school teacher in England who, following official reprimand at a disciplinary hearing of the General Teaching Council (GTC), was permitted to continue teaching. Unlike the GTC, who allegedly argued his behaviour was incompatible with professional norms, this teacher did not believe he was obliged to be a role model. His case illustrates a policing of sexual identities and prescriptive normative standards as being fundamental in importance to the moral universe of the profession's regulatory authority. Feminist theory rejects confining 
sexuality to the private sphere, arguing instead gendering and heterosexualisation structure public institutions and social life (Disch and Hawkesworth 2015). The power that results from the accrual of the authority annexed by association with heterosexualisation in tandem with hierarchical school structures is important for theorising the thorny political nexus of female student vulnerability.

The prominence of the topic of sex within school student cultures foregrounds the power of this discourse which inclines students to feel obligated in pursuing binary subjectivities, feminine or masculine (Epstein 1997; Sikes and Piper 2010). Arnot and Miles (2005) describe how historically embedded power over sex mobilises definitions of personhood and fosters heterosexual domination (Skeggs 2014). The historiography of rape in early modern England and Wales demonstrates the longevity of a patriarchal order: female victims of rape crime were vulnerable in the masculine institution of the law court and had low credibility as witnesses when making accusations about male perpetrators. Women who took their case to court were unsuccessful in gaining a rape conviction in London 1730-1830, for example, where female victims "stood a better chance of convicting their attackers if husbands and fathers prosecuted for them" (Watson 2013), and

\footnotetext{
"Welsh women seem to have been consistently regarded as less significant than men, both as the victims and perpetrators of violence: the voices of rape victims were unheard...Criminal justice in Wales reinforced gendered notions of the lesser status in society of women..." Watson (2013: 265)
}

Historical sociology of Victorian sexual behaviour identified differences between social classes in patterns of sexual behaviour outside of marriage in nineteenth-century Scotland; class-inflected masculine domination emerged in terms of how middle-class men sexually exploited lower-class females (Smout 1975). Lip service was paid to the sexual ideal of 
Christian teaching about chastity. Bourgeois males, disbarred from sexual contact with girls of their own class, sought it from working-class girls either through seduction of domestic servants employed, whose status made them "vulnerable to sexual exploitation" or use of prostitutes (Smout 1975: 56-57). Female prostitutes during 1835-40 were predominantly in their late teens - $66.2 \%$ were aged $15-20$ (p. 59). Feminists during the 1970 s have utilised the Marxist analysis of capitalism for critiquing patriarchy; in this historical case, working-class female servants and young prostitutes are dominated by the bourgeoisie, a critique extended to deconstruct domination of women by men which intersected with class (Oksala 2015).

The shaping of girls' construction of heterosexual relations and male dominance turns our attention to family-education ties (Arnot 2002a: 347). Female students learn to provide an emotional service to boyfriends and, as Arnot notes gender and class relations prescribe "interlocking dynamics" which can be transmitted not only through school, but in the bedroom, and elsewhere, where norms of emotional labour and heterosexuality are learnt (Wharton 2009). Dimensions of school student cultures are far from being barriers to the gaze of predatory adult sexuality. Schools have been found to be highly sexualized sites where struggles around sexuality are pervasive, and "of consuming interest and, at the same time, taboo" (Epstein 1997: 105): it was argued a "compulsory heterosexuality" underpinned the direction of the culture work on identity construction by students. Renold (2000) demonstrated similarly that during the final years of primary schooling dominant constructs of heterosexuality mould the identity work of these children, and the normal 'girl' is a heterosexual self.

Sexual issues occur beyond and above the student experience: studies of teachers in England and Wales found male teachers represented the largest occupational group of sexual abusers, and their victims were typically adolescent girls aged 12-17, a finding resonant internationally in the Netherlands and Zimbabwe (Moulden et al. 2010: 406). Sikes and 
Piper's (2010) studies of female pupils' allegations of sexual misconduct by their male teachers in English state schools draws our attention to the deeply normative nature of heterosexual dynamics and attendant identity constructions in classrooms and schools. Sikes and Piper (2010) propose the notion that this growing phenomenon of sexual abuse allegations against male teachers reflects a "contemporary moral panic". The UK's Trade Union Council poll of sexual harassment, not connected with teachers, found in 2014 that $59 \%$ of females aged 13-21 experienced it at school or college; $29 \%$ of $16-18$ year olds reported experiencing unwanted sexual touching at school and between 2012-2015 some 600 rapes in schools were reported to police (Harris 2017).

The sexualized environment of modern society, Sikes and Piper (2010) suggest, is a contributory factor to a growth in sexual abuse allegations. An alternative feminist theoretical perspective on such false allegation data is to argue they represent a challenge by adolescent girls to the male heterosexual hierarchy of a school's social order. Gender resistance by teenage lads took a more overtly violent and aggressive form, taken as symbolic of a working-class masculinised hegemonic identity: Paul Willis's Marxist analysis in Learning to Labour (1977) demonstrates compliance to hegemonies of class and gender whereby normative intersectional reproduction of class-gender relations is maintained.

In one a very few studies in the UK Page (2013) reminds us that misbehaviour of school teachers, unlike research on school pupil misbehaviour, is heavily under-researched. His analysis gives a descriptive classification of three hundred individual teacher GTC-recorded cases of misbehaviour committed between November 2009 and August 2011. He claims these GTC's disciplinary orders give "a glimpse into the range of misbehaviours enacted by teachers". Most disciplinary orders were issued against men both at secondary level and within the primary school sector despite there being fewer male than female teachers in both sectors, though with by far the greatest disparity being in primary schools. In the secondary 
and primary sectors men received respectively $74 \%$ and $55 \%$ of disciplinary orders. Offences reported to the police by the GTC included sexual activity, violence, substance abuse and driving offences. The more serious of these breaches occurred at secondary school level and included communications with pupils containing sexualized content and/or inappropriate physical contact with pupils. Page's discovery of the existence of gender bias in the phenomena of offending statistics was not subjected to sociological theorising.

Page (2013: 551) classifies the General Teaching Council (GTC) offending reports about individual teachers who were found guilty of offences in England as being "at the more serious end of the misbehaviour continuum" on the grounds that the offences threaten the welfare of pupils and undermine trust in the profession. Page restricts his documentary analysis of the data to analysis through the somewhat dated resource of Merton's (1968) conception called "middle-range theory". This construct of theory classes the notion of legality as a factor influencing decisions about categorising teacher misbehaviour and professionalism. Page suggests public trust is an "influencing factor in this emerging theory" (Page 2013: 559). That Page (2013) relied heavily upon literature from organisational science, managerialism, and psychology to frame the analysis of these data arguably confined theorisation, generating a neglect of contested, wider questions about teacher offending and how it might penetrate processes of social reproduction in unknown ways. But taboo may have interfered with the progression of a feminist analysis, possibly explaining a lacuna in addressing associated issues during identity formation in teacher education.

Beauchamp and Thomas (2009) argue that in teacher identity-formation literature little is said about emotions that teachers are forbidden to experience. Cultural contexts that teachers experience as citizens, through gendered processes of cultural transmission, impose habits that can prevent educational influence re-orienting their moral positions and teacher-identity (Kukari 2011). Beauchamp and Thomas (2009: 175) note that student teachers "must undergo 
a shift in identity as they move through teacher education ... identity shifts may occur throughout a teacher's career because of interactions within schools and in broader communities". Such an analysis arguably gives insufficient attention to the potential of an unresolved tension between the identity of individuals before they become teachers and the identity they are expected to have once they achieve teacher-status. A clash between the socialisation of a heterosexual male in society prior to joining the teaching profession, and a normative professional identity bound by prescribed codes of conduct about forms of legitimate communication with female pupils, may be avoided on the assumption that adherence to traditional heterosexual norms make sexual transgressions remote. This may be an unwarranted assumption; pre-teacher identity may survive professional induction and coexist with the new professional teacher identity.

\section{FEMINIST REPRODUCTION THEORY}

Feminist theory is necessarily oppositional to conventional heterosexual cultural norms which are exposed as contingent on historically embedded normativity. It aims to denaturalise what passes for human difference. Through a critical analysis of the complexity of power relations it often utilises intersectional analysis to deconstruct contemporary life in order to emancipate individuals from essentially political identities of servitude and deference that dominate what is authorised (Disch and Hawkesworth 2015). Feminist theory on cultural and therefore gender reproduction identifies that hierarchies of difference, stratifications, the naturalness of gender identity and heterosexuality are mistaken. Instead they are conceptualised as modes of dominance. The concept of embodiment in feminist theory is apposite to an analysis of the sexual offending addressed in the paper: the body is a site for the symbolic construction of sexual difference and a locus for subjectivity (Threadcraft 2015). As noted in the previous section, the female body is exploited in diverse ways, two being in terms its being a surface 
for the male gaze and carnal exploitation. Simone de Beauvoir $\{1949\} 1989$ describes how men utilise modes of gender power that engineer female passivity, docility and subordination. Also, the adolescent girl assimilates the identity that her body is there to be viewed, an object for voyeuristic pleasures.

Norms and normalising processes are fundamental to contemporary feminist analysis and praxis where norm production and maintenance in heteropatriarchal social and cultural formations are interrogated (Spade and Willse 2015). Michel Foucault's work is appropriated to highlight the disciplinary subjection of individuals' bodies and minds. 'Beauty norms' for example, or 'sexual attractiveness norms' are enforced, forcing women into the servitude of these boundaries and affecting their thriving. It is the truth effects of normative discourses that construct this illusory patriarchal world. Processes of normalisation are covert in social structures, but through critical interrogation of norms feminist theory exposes these iron cages, how they are invented and "other". The field of regulation in schools, being identified already as sexualized in heterosexual norms, will impose truth effects that constrain identities, but also legitimize the behaviour of others whose actions rest upon established gender normativity with the hegemony to bestow upon their user the power to prescribe options through privileged access to repertoires of punishment. Foucault presents modern power as disciplinary where norms of regulation impose standards and prescribe appropriate ways of behaving, appearing and moving, including interpersonal sexualized communication. Ervine Goffman's micro-sociology of everyday life demonstrated the ways in which social norms and identities are manipulated because normative ground rules pre-exist about presentations of the self (Oksala 2015; Spade and Willse 2015).

Foucault's multi-faceted analysis of dynamic, shifting rationalities and technologies of power bring to the surface the relational nature of power as an action. Through networks and supporting technologies engulfing society a "microphysics of power" governs schools, 
families and working-practices. These power relations are diffuse and intermeshing. Secondwave feminism emphasised the exposure of power relations in the private sphere of female experience, including sexuality. Gender norms about sexuality produce truth effects which exercise power and control over socially approved identities for men and women (Oksala 2015). As a socially constructed process it is implicit in the emergence of a caring subjectivity through vocational training regimes (Skeggs 1988). The dynamic is again present in the tensions underlying the false sexual accusations reported in English classrooms (Sikes and Piper 2010). The resistance identity critique that arguably characterises teacher identityformation literature illustrates the power of conventional gender normativity to constrain illustrates the power of truth effects of a dominant social convention (Beauchamp and Thomas 2009). The power/knowledge networks and disciplinary habits induced by and with teacher education authorise only some subjectivities and narrative voices (Bartky 1988; Butler 1990). Through conforming to male patronage women must internalise patriarchal norms and imbibe standards of erotic femininity (Beauvoir; \{1949\} 1989; Low 2006: 127).

Scholars of cultural reproduction are familiar with the ways in which macrosocial processes are intertwined with individual biographical experience (Collins 2009; Skeggs 1988). Masculine domination is greatest in social fields where the maintenance of the social order is pivotal, and, as historiography records, has been established in class and gender terms for centuries (Bourdieu 1998). Education, for Bourdieu, is formative of societal reproduction and therefore normativity is foundational to the logic of its practices including reproduction through educational processes of class reproduction which canonize, through pedagogic communication, social and symbolic place location (Bourdieu and Passeron 1977; Arnot 2002b; Maxwell and Maxwell 1995). Bourdieu (2002) formulates social reproduction by emphasizing the positioning of social agents who embody the rules of a social world in which they are embedded, and act on these rules and their history of occupying a social space. The 
'habitus' is the socialized formation representing an identity and is generative of thoughts, perceptions and actions. Together with cultural, social and symbolic capital social agents become positioned in a distinctive social space, and as discussed below, school students experience pressure to conform to heterosexual norms.

Gender relations are routinely re-contextualised, produced and reproduced through education as conceptualised by social reproduction theory (Arnot 2002b; Arnot and Miles 2005). Gender codes are, as this paper reports, enacted during sexual transgressions which contribute surreptitiously to masculinizing schooling and ensuring its continued contextualisation in patriarchy as offending heterosexual male teachers produce and reproduce constructions of identity. Bev Skeggs (1988: 131) demonstrated how young working-class, white English women learned to occupy a subjugated position through developing a habitus, being taught a vocational caring curriculum's social and symbolic entrapment that "involves them in the construction of subjectivity and gender and class reproduction...they socialise themselves out of the labour market and establish familial responsibilities" (see Bartky 1988). Cultural reproduction is mobilised as these women engage with a prescribed gender identity and learn scripts which directs aspiration to domesticated subject positions. Arnot and Miles (2005:181) remark that New Labour's education policies during the 1990s carried the "inherent danger" that girls would form the impression "that the world is male dominated". In the next section the claim of male domination is examined in the context illicit secretive encounters pursued against female students, encounters that, it is argued, are a neglected factor in our knowledge of cultural and gender reproduction.

\section{THE RESEARCH STUDY: PROFESSIONAL CONTEXT}


Societal systems attempt to impede moral and behavioural contamination of professional landscapes especially when a Duty of Care to young persons is required. It is a legal requirement for teachers working in Scottish state schools to be registered with the GTCS and to self-govern themselves through respect for its core professional values. The Council's aims include setting and improving professional standards and its Director of Governance can deliver what is called a 'Fitness to Teach' investigatory process. In 2012 the Scottish Government granted independence status to the GTCS, whose fifty-year history is colourfully charted by former officer Ian Matheson in his book Milestones and Minefields. The GTCS's Code of Professionalism and Conduct relies upon what it calls "personal regulation based upon common sense and good professional judgement". It sets out the values to which teachers are expected to adhere "both within and out with the classroom", stressing the importance of the maintenance of trust in the profession throughout society. Explicit guidance is given about behavioural boundaries; examples include: no discussion of intimate or personal relations with pupils; avoiding being involved with pupils' personal affairs; not participating in social networking sites to communicate with pupils nor engaging in substance abuse, violence or criminal activity (Code: GTCS 1.2.03.12; and see www.gtcs.org.uk). Hearings about 'Fitness to Teach' respond to complaints raised by the teaching establishment and submitted by members of the public. GTCS sanctions include Reprimand, Conditional Registration Order, Removal of Registration, Refusal of Application for Registration, and Referral under the Protection of Vulnerable Groups (www.gtcs.org.uk/uk/copac).

\section{GTCS: Data Sources}




\section{Quantitative Data Source: 2005-2015}

Emailed requests to the GTCS by the author under Freedom of Information legislation produced the disclosure of the numerical figures and their classifications as set out in two tables below. As concluded below, male teachers, especially in the secondary school sector, offend to a higher degree. These data exhausted what could be provided under this law' as well as what was available from the organisation's administrative systems as used by the GTCS itself to record offending and related unprofessional conduct. These data are consistent with the results Page (2013) discovered about teacher offending in England.

Tables 1 and Table 2 show GTCS disposals of 174 cases brought before the GTCS professional panel during the period 2005-2015. The workforce at this period splits, almost equally, into primary and secondary teachers. These 174 convicted teachers, a very small proportion of the Scottish school teaching workforce, were 'Removed' from the GCTS teaching register. In May 2016, 73,306 teachers were registered for teaching. The offending teachers identified comprise less than $0.24 \%$ of this teaching workforce, but males as opposed to females constitute a significantly larger proportion of the $0.24 \%$ calculation; in terms of 'Removed' tariff, males, at the raw figure of 126 , are $0.17 \%$ of those convicted, whereas females, at the raw figure of 46 , are $0.06 \%$ of the 73,306 work-force.

Examining the data in Table 1 first we discover more offences are committed by male teachers than by female teachers: combining primary and secondary figures on 'Removed' the severest sanction - there were 126 males compared with 46 females. The figure of 19 for male secondary teachers disciplined through 'Reprimand' is significantly higher than for females numbering 7 in this category, a pattern that is also consistent with 'Reprimand Consent Order' gendered proportions. Exploring Table 1 by sector and male gender there are, across the three disciplinary sanctions, 132 males located in secondary schools and only 22 in 
primary which may suggests differences in the cultural ethos and professional dispositions of staff working with older students. Male teachers working with the approximate age range 1218 years commit more offences compared with those working with approximate ages 5-12 years in primary schools.

Whilst it is the case that females outnumber males in primary school teaching, male teachers nevertheless commit a similar number of offences as female teachers which iterates with other comparisons in this GTCS data source, foregrounding male gender as more critically implicated in offences in general, a pattern that triangulates with the qualitative data from GTCS below. In the secondary sector where the proportion of male staff to female staff is historically greater than in primary schools, the proportion of male teachers who offend is greater than the proportion of female teachers who offend. Turning to the data in Table 2 sexual offending - numbers 68 offences out of a total of 174 the disposals from the same GTCS data archive expressed in Table 1- merits the severest tariff. These GTCS descriptive statistics give a context for wider patterns of offending, with the magnitude and tariff of sexual offending meriting the emphasis this paper adopts. The gendered and school sector pattern identified in this GTCS data is consistent with Page's (2013) GTC in England disciplinary findings.

INSERT TABLE 1 HERE

INSERT TABLE 2 HERE 


\section{GTCS Qualitative Documentary Data}

\section{Qualitative narratives}

The qualitative data generated for the purposes of this study are taken from a historic twelvemonth period where they had been published on the GTCS's public website. 'Fitness to Teach' case details describing the offences and disciplinary hearings of thirty-one teachers were published and archived for twelve months. This disclosure of convictions is GTCS policy and is ongoing. Twenty-three of the thirty-one were secondary teachers and eight were primary teachers; eighteen of the thirty-one are male and thirteen are female. The illustrative extracts used below originate from this official historic data. They are typical of the offences of a sexual category recorded on the GTCS's website space dedicated to this matter. Although the cases had previously been in the public domain the researcher also requested and received permission from the GTCS to utilise them in academic research. Two sections have been developed linked with two figures to present the results of the analysis of these data.

In view of the sensitive nature of the subject matter, identifying details about schools and teachers have been deleted, for ethical reasons, by the researcher from the extracts used. Although the GTCS has a policy purpose in publishing these identifying details, this is not necessary in a research study where confidentiality and anonymity are paramount. For reasons of space, and in the light of the prominence of offences of a sexual nature in the dataset accessed relative to other offences, the paper concentrates exclusively on the microsociology of this transgression which speaks directly to feminist theory and the review of the literature. 


\section{Cultural Reproduction, and Identity Exploitation}

The model in Figure 1 was created to represent the conceptual geography of sexual offending by teachers. It is analytically sensitized to the research questions and to feminist theory. In Figure 1 the cultural reproduction of transgressions occurs in several different venues including the use of photography to capture a projected sexualized appearance. Each of the four venues are under the control of men who design their exploitative affordance from these sites, as will be discussed shortly through illustrative extracts. The schematic conceptual description in Figure 1 indicates the expression of a micro-physics of patriarchal power. As the extracts below Figure 1 illustrate, the projection of power takes place through different 'genres of control' over embodiment, and the projection of self-serving sexualized identities onto others. The organisation of the discussion of Figure 1 is clockwise, beginning with the cultural geography of the hotel.

\section{INSERT FIGURE 1 HERE}

The hotel setting draws upon a romantic adult myth of sexual adventure and the liminality of this seductive territory, neither domestic nor educational, where alcohol consumption and bodily intimacy are normal. The teacher uses this space as a place of impersonal relationalities given that it exists after the "school's Sixth Year" and is situated beyond the school precinct in the anonymous setting of the international Travelodge. The reference to "approximately three hours" symbolizes it as being accessed for a purpose other than overnight accommodation. Domination in the form of embodiment is manifested during the encounter described in the charge: 
“...whilst employed as a teacher.... and following the school's Sixth Year, you did accompany Pupil A and other pupils to the Travelodge, where you did have inappropriate contact with Pupil A, in that you did: Spend approximately three hours alone with Pupil A in an hotel room. Share an alcoholic drink with Pupil A (age 17 at the time). Share a bed with Pupil A. Repeatedly engage in sexual activity with Pupil A...”

Sexualized gender reproduction through internet technology intrudes upon the identity and experience of the female student in a more psychologically expressive way compared with the planned seduction at the hotel. Several threads of offending practices emerge from the choice of this communication platform; in the first one it seems that participation in an abusive community illustrates dominance through a collective practice of sharing illicit and disturbing material:

“...unknown you did send, by means of a public electronic communications network messages to another person, that were grossly offensive or of an indecent, obscene or menacing character, in that you did converse regarding the sexual abuse of children..."

Facebook is the gateway in another case where the focus takes a dyadic form designed to provoke a sexually resonate subjectification to a student it seems who was known to the teacher involved:

\footnotetext{
"Between May and on exact date unknown, within a message on Facebook, you commented to [fourth year pupil] that she was "photogenic" ...during a conversation you were having on Facebook with [fourth year pupil], you did make inappropriate comments to her..."
}

Exchanges of more direct flirtatious heterosexual meaning expressed under the cover of a word game and chatting designed to foster an inappropriate relational situation are apparent 
in the following attempt at creating clandestine intimacy and shift identity boundaries is illustrated in the following charge,

"you did contact Pupil 1 via the online game "Word Feud" using the chat facility; Thereafter make inappropriate comments during an online chat conversation with Pupil 1, including stating inter alia: “No you haven't, you've been dancing. Let's just say you have been revising all night and I'm not texting a pupil, it can be our secret." Mobilising photography introduces the male gaze and the surface of the embodiment of sexual identity; in the next extract the charge draws attention to an abuse of power through breach of trust:

“...being a person who was in a position of trust towards $\mathrm{X}$ then aged 15 years, whilst said X was a pupil at ... and you did look after her at said .... Academy, did engage in a sexual activity with a person who was under 18 years in that you did request that she send you an indecent image of herself and you did tell her that you wanted to kiss her; you did intentionally send a written sexual communication to ... a child who had attained the age of 13 years, but had not attained the age of 16 years, in that you did induce her to send you indecent images of herself and advised her that you wanted to kiss her..."

The female students are assigned a subjugated status by the teacher, whose controlling desire is reflected in the abusive actions that he instigates. A second extract involving photography illustrates a different abuse technology outside of the school precinct which produced fear and alarm,

“On January 2010 at [city], you did conduct yourself in a disorderly manner, use your mobile phone to take a photograph and make visual images of $\mathrm{X}$, while she was in a 
state of undress within the shower cubicle in a room there, thereby placing her in a state of distress and alarm and you did thereby commit a breach of the peace..."

Finally, a geography of reproduction also occurs in the hierarchy of the school itself: the offending occurs within the hierarchic culture of classrooms. Shaming as emotional control is aggravated by presence of the victim's peers. The 'gamesmanship' with sexual connotation is a pretext for this predation:

"at [High School], you did attempt to open a zip on the shirt of [third year pupil] and thereafter attempt to place a two-pence coin into the zip...."

"During the 5th year session for Pupil 1, between August 2012 and June 2013, in a classroom at [High School A], you did ask [a sixth-year pupil], in front of a registration class, "is it your time of the month?" On exact date unknown, prior to September $2013 \ldots . .$. in a class room at [High School A], you did comment to [a sixth-year pupil] that "you must be used to that the morning after..."

His rhetorical question about the female students' menstrual cycle demeans and humiliates, traducing her personal identity to a mere biological being without agency except that based on a female biological process. His derisory question aims to manipulate through humiliation. It is a technique of control and predatory domination. That his unpleasant remark is repeated illustrates this teacher's determination to reduce femininity to mere biological processes.

\section{Power and Gender Domination}

The theoretical project of feminism is to eradicate power relations through exposing and understanding them (Oksala, 2015). Relations of domination and coercion are described in the preceding section where the concept of patriarchal geographies of reproduction is designed to emphasize the role of places in reproducing power relations of abuse. The notion of taboo makes the disposition to report abuse difficult for two reasons in this context, firstly 
the power is exercised from a hierarchy of trust-relations over the student, and secondly, the subject matter itself, sex, is traditionally a private, taboo field. The forced compliance of the victims is constrained, like those of the slave in an analogy drawn by Oksala (2015) based on Mary Wolstonecraft's polemic $A$ Vindication of the Rights of Women.

Using the same qualitative data-set the analysis in this section explores further the physical sites of transgression set out in Figure 1. In Figure 2 the abstract conceptualisation illustrates flows of power through embodiment in its different and related features. Each feature named in the peripheral circles of Figure 2 have their truth effects from the foundational ontology of heterosexual normativity situated in the central circle. The adoption of this complementary figurative model for theorising gender domination is designed to emphasize the processes and mechanisms associated with the places and materials which offending exploits.

\section{INSERT FIGURE 2 HERE}

The organisation of the analysis in this section follows the approach adopted for Figure 1 and begins with practices of degradation and by implication "othering". Degradation pervades every one of the extracts in the previous section, which illustrate the deleterious nature of the actions. Demoralisation is a goal of degrading which, through an abuse of normative heterosexual male gender, only a demeaning biological status is publicly authorised for a female student, in front of her morning registration class the question, "Is this your time of the month?" and "you must be used to the morning after" are not questions or other genuine communicative acts. Instead the delineation of the female identity is aggressive and shameful. This and cognate communications through mechanisms of taboo intrude and are disruptive to wellbeing. Text messaging, despite its reciprocal social potential in this offending dialogic, represents the denial of the student's personhood as age and status are asymmetric; for instance, a teacher did "on dates unknown.... at various places ... send repeated text messages to a girl then aged 12 years of age which were inappropriate and romantic in nature...." And 
"on another occasion, when you were informed that Pupil 1 had been practising dancing, you replied, "Wish I could see that"."

Appearance is a bodily site that is sometimes the target of conveyances of gender domination. The projection of a constructed heterosexuality is apparent on several occasions which are demonstrative of the teacher-perpetrator's 'methodology' of norm production, using himself as the exemplar of heterosexual desire. The Facebook message extract, "you commented to [fourth year pupil] that she was "photogenic", relies for its intended effect on two things: firstly, Facebook is a popular and intimate online technology. In some contexts, the teacher's remark might seem acceptable but here it reflects a breach of professional code and symbolises inappropriate intimacy with a grooming intention: the real purpose of uttering "photogenic" is to seduce, not simply admire. This expression of clandestine desire etches on the female student a reminder that she is judged through bodily appearance which is valorised if it provokes male sexual desire. Appearance is also evoked with a similar meaning in the charge of inducing the victim to send indecent images of herself. Communication of this nature is likely to naturalise a predatory heterosexual normativity, and the sexualisation of the female identity becomes an object for exploitative appropriation, illustrated in the charge of making visual images of the victim while she was in a state of undress.

Bringing the female students under the sway of a sexualized microphysics of predatory power undermines and fosters vulnerability. The normalized practices of the game invite participation, but the real intent is to dominate for personal gain. The game invents and enforces the fabrication of female identity as a merely passive object on whose 'surface' manipulative heterosexual games are enacted. This process of gender domination also occurs through tactile intrusion - "you did attempt to open a zip on the shirt of [third year pupil] and thereafter attempt to place a two-pence coin into the zip" - where gaming strategy is used to 
manipulate and win control over the female body whose movements are now monitored, the object of the male sexualized gaze. Other tactile superimpositions of dominance although of a less immediate character include valorisation of bodily image, surrendering of images and flattery about appearance. The appeal to tropes of attractive appearance is illustrated, for example, in the charge that the perpetrator did "say to other pupils at the school that Pupil 1, then a pupil at [High School] in your class, was "lovely" and at another time, that Pupil 1 was your "favourite pupil".

The biological dimension in Figure 2 is designed to emphasise the biopolitical strand of feminist theory and identify its representation in the data. Biopolitics is associated with the medicalisation of persons and societies (Oksala 2015). As previous discussions in the findings section illustrate, these teachers operate through what Basil Bernstein has called “invisible pedagogies" (see Arnot 2002b: 584). The biological in our results is synonymous with sexuality and sexual practice. The two references to the menstrual cycle of female fertility are paradigmatic examples of the use of bio-power. The reproductive affordance of bio-power occurs through references to "engage in sexual activity" during the Travelodge visit. The biological effects of alcohol consumption on individual resistance privilege this power in the context of illicit seduction. Bio-power inscribes itself on bodies: the game with the student's clothing zip conveys one example of its bodily focus; in another case the physicality of bio-power presents through allusion to dance and movement.

The mechanisms of reproduction that the discussion of Figure 2 foreground associate the patriarchal culture with an essentialist view of gender and gender relations. Ancient norms of heterosexuality and their societal paths are apparent throughout the charges presented, which are consistent with the literature review findings. As an offending 'pedagogy' the actions described are designed to repress female agency and reproduce exploitative gender binaries. Insincere clandestine practices pretend to offer vulnerable young people friendship. These 
types of seductions and vicarious thrill-seeking must be understood in terms of their relationship with teacher status and professional norms. It is the exploitation of the latter that is reflected in the forms of power and subjugation which these practices represent. The perpetrators draw upon their professional authority, and a generic male patriarchal power in the school setting which disposes students to defer more readily and become amenable to exploitation and its abuses.

\section{CONCLUSIONS}

The extensive use of internet-facilitated communication technology in the offending behaviour seeping into and disrupting the intimate lives of school students, described above, situates the focus of this paper on modernity's dark side (Alexander 2013). Deployment of mobile technology and images facilitated predatory masculinity's entry into the private social spaces of students within and beyond the school gates. The gender-dominating effects of sexually and professionally aberrant behaviour nest themselves in pre-existing heterosexual climates in the wider society and known to us, as indicated through the research review. The normativity of this representation of teenage sexuality in the literature reveals to us a social landscape connected with schooling, involving perpetrators and victims. It constrains and stultifies human flourishing and is a surreptitious 'invisible pedagogy' abusive of trust. Skeggs (1988) explains gender reproduction through a vocational caring curriculum which, for the young female students, was what she termed a "domestic apprenticeship". The sexualisation of female school students by teachers represents the indirect production of a damaging "heterosexual apprenticeship" affecting the lived experience of these student victims. The GTCS removed these teachers from its teaching eligibility register. As noted in the literature review male exploitation of younger vulnerable females has a long history, and the data in this paper suggests there is a disturbing and persistent continuity of abuse. 
The quantitative results reported indicate the offending identified is concentrated in secondary schools. This discovery is of sociological significance: it arguably reflects the coexistence of factors which would have been capitalised upon by teachers for their gratification. The age period 12-18 involves maturation of sexual identities. Capitalism exploits this emergence of sexuality and its apparent needs, offering role models and lifestyles associated with sexualised celebrity culture. The quest for intimate personal relations outside the family nexus also makes the exploitation described more likely. For these reasons the interpretative analysis and the literature acknowledge how the culture of the school as a heterosexual institution for both teaching staff and students is subject to a broader, deeply sexualized society whose emphasis on appearance and attractiveness undoubtedly impacts upon the dynamics identified in the paper (Sikes and Piper 2010). Very little is known about the wider biographies of the teachers involved, making it impractical and speculative to develop a thesis about how the heterosexual normativity of the adult social space was not containable by a moral authority of the teaching profession. A policy implication is that the lure and obsessive sexuality that commentators argue characterises modernity ought to be subject to more attention during the training and socialisation of teacher identity. The hypothesised co-existence of a dual identity earlier in this paper should not be overlooked as forming a part of the nexus explaining the offending. The intensification of safeguarding policies and general monitoring of professional behaviour does not arise in a sociological vacuum. The findings of this paper endorse the importance of these policies, but it does not end there. The focus of the feminist analysis offered in this paper encourages us to recognise deeply entrenched forms of power constitutive of the patriarchal order of society.

\section{Acknowledgements}

I am grateful to the BJSE reviewers for providing immensely constructive comments. 


\section{References}

Alexander, J. C. 2013. The Dark Side of Modernity. Cambridge: Polity Press.

Arnot, M. and P. Miles. 2005. "A Reconstruction of the Gender Agenda: The Contradictory Gender Dimensions in New Labour's Educational and Economic Policy" Oxford Review of Education 31 (1): 173-189.

Arnot, M. 2002b. "The Complex Gendering of Invisible Pedagogies: Social Reproduction or Empowerment?" British Journal of Sociology of Education 23 (4): 583-593.

Arnot, M. 2002a. "Making the Difference to Sociology of Education: Reflections on Family-School and Gender Relations." Discourse: Studies in the Cultural Politics of Education 23 (3): 347355.

Bartky, S. 1988. "Foucault, Femininity and the Modernising of Patriarchal Power." In Feminism and Foucault: Paths of Resistance, edited by I. Diamond and L. Quinby, 61-85. Boston: Northwestern University Press.

Beauchamp, C. and L. Thomas. 2009. "Understanding teacher identity: an overview of issues in the literature and implications for teacher education." Cambridge Journal of Education 39: 175189.

Bourdieu, P. 1998. Practical Reason: On the Theory of Action. Stanford: Stanford University Press.

Bourdieu, P. and J.-C. Passeron. 1977 Reproduction in Education, Society and Culture. London: Sage.

Bourdieu, P. 2002 Outline of a Theory of Practice. Cambridge: Cambridge University Press.

Butler, J. 1990 Gender Trouble. London and New York: Routledge. 
Collins, J. 2009. "Social Reproduction in Classrooms and Schools." Annual Review of Anthropology 38: $33-48$.

Dillabough, J. 2003. "Gender, Education and Society: The Limits and Possibilities of Feminist Reproduction Theory." Sociology of Education 76 (4): 376-379.

Disch, L. and M. Hawksworth, eds. 2015. The Oxford Handbook of Feminist Theory. Oxford: Oxford Handbooks Online.

Douglas, M. 1966 Purity and Danger: An analysis of concepts of pollution and taboo. New York: Praeger.

Epstein, D. 1997. “Boyz' Own Stories: Masculinities and Sexualities in Schools.” Gender and Education 9 (1): 105-116.

Foucault, M. 1978. The History of Sexuality, Vol. 1, An Introduction. Translated by R. Hurley. London: Penguin.

Foucault, M. 1982. "The Subject and Power." In Michel Foucault: Beyond Structuration and Hermeneutics, edited by H. Dreyfus and P. Rabinow, 208-226. Hemel Hempstead: Harvester.

Freud, S. 1950. Totem and Taboo. London: Routledge, Kegan and Paul.

Harris, S. 2017. "Stamping out sexual harassment in schools." The Scottish Educational Journal 101 (3): 22 .

Kukari, A. J. 2011. "Cultural construction of indigenous pre-service teachers' identities prior to teacher education." Contemporary PNG Studies: DWU Research Journal 15: 134-145.

Low, M. 2006. "The Social Construction of Space and Gender." European Journal of Women's Studies, 13 (2): 119-133.

Maxwell, J. D. and M. P. Maxwell. 1995. "The Reproduction of Class in Canada's Elite Independent Schools.” British Journal of Sociology of Education 16, (3): 309-326.

Milner, N. 2012. "Taboo." In The Oxford Handbook of the Archaeology of Ritual and Religion, edited by T. Insoll. Oxford: Oxford Handbooks Online. 
Moulden, H. M., P. Fireston, D. A. Kingston and A. F. Wexler. 2010. “A Description of Sexual Offending Committed by Canadian Teachers.” Journal of Child Sex Abuse 19 (4): 403-418.

Oksala, J. 2015. "Microphysics of Power." In The Oxford Handbook of Feminist Theory, edited by L. Disch and M. Hawksworth. Oxford: Oxford Handbooks Online: 1-23.

Page, D. 2013. "Teacher misbehaviour: an analysis of disciplinary orders by the General Teaching Council for England.” British Educational Research Journal 39 (3): 545-564.

Reynold, E. 2000. “Coming out': gender, (hetero) sexuality and the primary school." Gender and Education 12 (3): 309-326.

Sikes, P. and H. Piper. 2010. Researching sex and lies in the classroom: Allegations of sexual misconduct in schools. London: Routledge.

Skeggs, B. 1988 “Gender Reproduction and Further Education: Domestic Apprenticeships.” British Journal of Sociology of Education 9 (2): 131-149.

Smout. C. 1975. "Aspects of Sexual Behaviour in Nineteenth Century Scotland." In Social Class in Scotland: Past and Present, edited by A. A. MacLaren, 55-85. Edinburgh: John Donald Publishers.

Spade, D. and C. Willse. 2015. "Norms and Normalisation." In The Oxford Handbook of Feminist Theory, edited by L. Disch and M. Hawksworth. Oxford: Oxford Handbooks Online: 1-24.

Steiner, F. 1967. Taboo. Harmondsworth: Penguin Books.

Watson, K. D. 2013. "Women, violent crime and criminal justice in Georgian Wales." Continuity and Change 28 (2): 245-272.

Wharton, A. S. 2009. "The Sociology of Emotional Labour.” Annual Review of Sociology 35: 14765.

Willis, P. 1977. Learning to Labour: How working-class kids get working-class jobs. New York: Columbia University Press. 
TABLE 1

2005-2015 Disposals: Teachers Removed / Reprimand Consent Order / Conditional Registration \& Reprimand- All Offences

\begin{tabular}{|c|c|c|c|}
\hline Gender & Removed & $\begin{array}{c}\text { Reprimand } \\
\text { Consent Order }\end{array}$ & $\begin{array}{c}\text { Conditional } \\
\text { Registration/Reprimand }\end{array}$ \\
\hline $\begin{array}{l}\text { M - } \\
\text { Primary/Secondary }\end{array}$ & 126 & 8 & 20 \\
\hline F - Primary/Secondary & 46 & 6 & 8 \\
\hline Further Education & 2 & & \\
\hline TOTAL & 174 & 14 & 28 \\
\hline
\end{tabular}

\begin{tabular}{|l|r|r|r|}
\hline \multicolumn{1}{|c|}{ Sector } & Removed & Reprimand & \multicolumn{2}{c|}{ Conditional } \\
& & Consent Order & Registration/Reprimand \\
\hline M - Primary & 20 & 1 & 19 \\
\hline M - Secondary & 106 & 7 & 1 \\
\hline F- Primary & 22 & 3 & 7 \\
\hline F - Secondary & 24 & 3 & 19 \\
\hline M - Further Education & 1 & & \\
\hline F- Further Education & 1 & & \\
\end{tabular}




\begin{tabular}{|l|r|r|r|}
\hline TOTAL & 174 & 14 & 28 \\
\hline
\end{tabular}

TABLE 2

2005-2015: Reasons for Removal from Register

\begin{tabular}{|l|r|}
\hline \multicolumn{1}{|c|}{ Type of Offence } & Removed \\
\hline Sexual/Sexual against & 68 \\
\hline Conduct & 37 \\
\hline Competence & 18 \\
\hline Drugs & 5 \\
\hline Firearms & 1 \\
\hline Fraud & 19 \\
(application / & \\
\hline Crimes of dishonesty) & 5 \\
\hline Motoring & 7 \\
\hline Public Order & 14 \\
\hline Violence/Violence & \\
\hline against a child & \\
\hline
\end{tabular}


\begin{tabular}{|l|r|}
\hline TOTAL & 174 \\
\hline
\end{tabular}

\section{FIGURE 1}




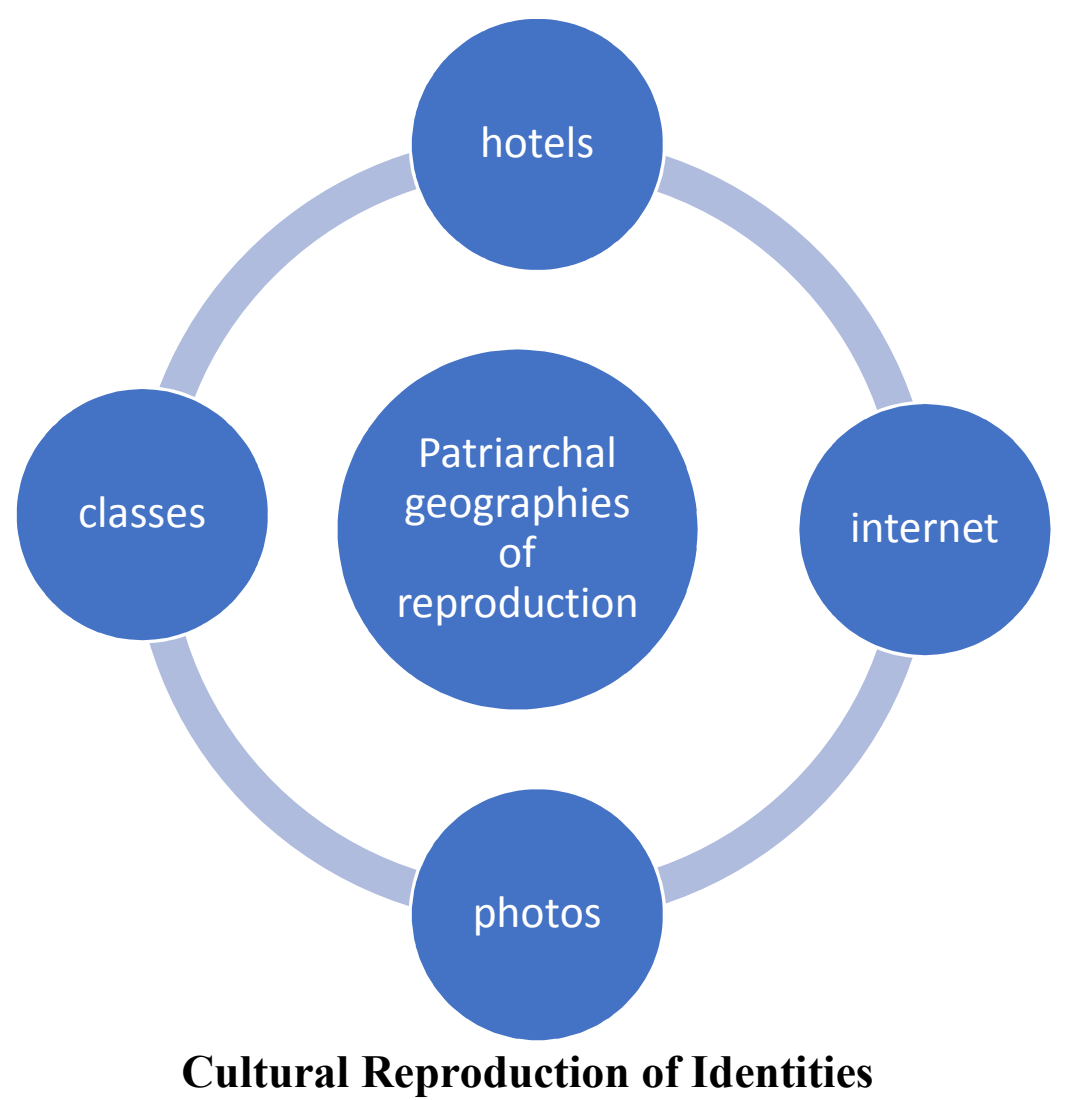

\section{FIGURE 2}

\section{Power and Gender Domination Appropriations}




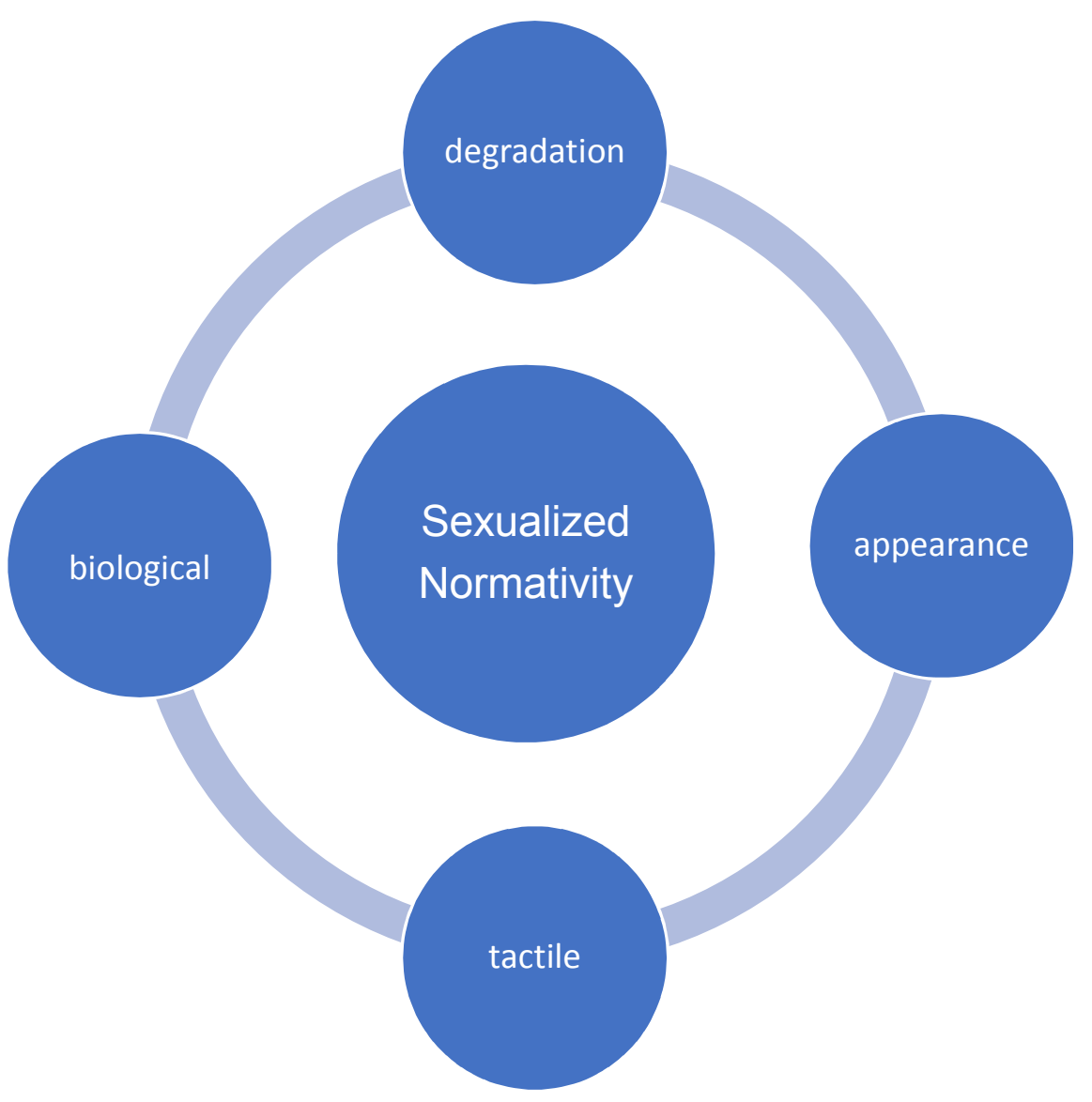

WORDS: 7,940. 